\title{
Research on Field Practical Course Creative Training for Primary Education Specialty
}

\author{
Jun Yang \\ School of Education and Sports, Bohai University, Jinzhou, 121013, China \\ yj690213@126.com
}

Keywords: primary education specialty; field investigation; practical course; creative training

\begin{abstract}
For the development of primary education specialty, the exploration of the students out of the campus, into the nature, to take part in learning, practical learning, research learning and other ways to study the field of the main form of field practice teaching. Through the investigation and analysis of the status, carried on the research of the course goal design, course content selection, course resources development and utilization, the course study evaluation, the field practical course pattern analysis and so on, and provides the concrete plan. Through the field practice of creative training, fully embodies the combination of theoretical teaching and scientific research practice, not only can cultivate students' practical ability, but also helps students to develop good qualities of working hard, seeking truth, and sharing the good quality of cooperation.
\end{abstract}

\section{Introduction}

The field practical course is a comprehensive practice activity course that students go out of the campus, go into nature, take part in learning, practice learning, research learning and so on under the guidance and organization of the teachers. Among them, the "field" is limited to the implementation of the course is not within the school, nor is the social environment, but the natural environment, such as mountains, hills, rivers, oceans, lakes and other geographical environment, the diversity of these fields determines that the practical content is multi discipline and comprehensive. The term "practice" specifies the practical nature of the course and points out the way of teaching and learning of the course. The term "course" made it clear that it was in the professional training program, and provided the inherent requirements of the course. Therefore, the diversity of the natural environment in the field determines the multi discipline and comprehensive of practical content. At this stage, the structure of the primary school course is generally composed of the branch course and hybrid course, subject course and activity course, unity course and selective course. Among these courses, the hybrid course, activity course and selective course are non presupposition, but they are mainly derived from three dimensions: students, society and nature. The design of the field practical course of primary education specialty is directly directed to the natural dimension, specifically speaking, corresponding to the comprehensive practical activity curriculum and school curriculum in primary school, it is also related to the primary school science curriculum, and hence it is the practical needs of development of primary education specialty. From the perspective of first and post course of the cultivation plan of primary school specialty and the combination of theoretical and practical courses, the field practical course is "Introduction to humanities and Social Sciences", "Introduction to natural sciences", "integrated practical activity curriculum design and implementation" in the cultivation plan of post course or accompanying course, which is conducive to the implementation of the combination of theory and practice [1]. 


\section{Research Status}

In recent years, the research on the field investigation and training are the University's sports specialty which is from the angle of sports development training, field survival training, orientation training and so on; The Geography, physical geography, petrology and so on; general biology, environmental ecology; pharmaceutical botany; exploration technology and engineering; and the field of students survival training [2]. Most of them are from the view of professional, the study is suitable for the characteristics of the field survival training program, or the construction of the field practice teaching base; They also study some talk about the professional ability, scientific thinking and practical ability. But with the characteristics of primary education specialty, the text of the field survival training is also very few. Mentioned several times in the primary school teachers professional standards, the national long-term development reform outline, to the develop students' practical ability, innovative thinking and so on. Therefore, the study of elementary school teachers in professional field practice is necessary and timely, with practice, theoretical value and innovation significance.

\section{Design on Course Target}

In the field of knowledge and skills, the accumulation of scientific facts and perceptual knowledge, to complement and enrich the field knowledge, inspection and improvement of the existing knowledge, deepen the understanding of the relevant scientific concepts, scientific principles and scientific theory, training and proficiency in the field of observation, field measurement, specimen production and other skills;

In the field of process capability, the ability to develop knowledge, scientific inquiry and scientific inquiry ability, field practice and work ability, the development and utilization of local curriculum resources, the design and guidance of natural research activities, and to lay the foundation for the development of curriculum resources development and the related practical activities;

In the field of emotional attitude and values, in close to nature, to appreciate the nature of the emotional experience, to cultivate a love of natural affection, to develop the awareness and behavior of respect for nature, love nature, and establish a harmonious development of human and nature, sustainable development of ecological civilization values, based on the experience of field practice "difficulties", the field survey "rigorous" to develop working hard , truth-seeking and truth-seeking, sharing and collaboration, enhance understanding of field workers in science and nature of science [3].

\section{Selection on Course Content}

According to the characteristics of the curriculum goal and the primary education specialty, we should carry out the field investigation in the field practice course content, on the one hand, we should determine the specific content and basic requirements from the natural geography, human geography and landscape diversity, dynamic (vegetation), and to reflect the basic and scientific nature of natural science; On the other hand, we should expand the human nature and life from the dimension of human, nature, society, and make the content focus on the basis of science, stress the basic, pay attention to the synthesis, attention experience and application [4].

Natural geography: the basic characteristics of the investigation and understanding of the practice of regional natural environment and natural elements; understand the practice area of natural and geographical overview; survey the main natural resources of practice area and its economic value.

Human geography and landscape diversity: to understand the nature, human tourism resources and their development and protection in the practice area, and to put forward some suggestions.

Animal and plant ecology: investigate the main types of vegetation and soil in practice area, 
vertical distribution of vegetation and soil, master basic method of field investigation of vegetation and soil;; the basic situation of animals and plants of the investigation, the relationship between animals and plants, distribution and environment.

Animal and plant taxonomy: to learn field records, specimen collection and production; learn to use or make up the brake, plant search table, learn to plant and animal classification, to identify common local animals and plants, to understand the local economic flora and fauna.

The fun of the game: The content can make full use of traditional games, folk games, optional game, self-made game etc., abandon the previous tedious diushou Juan, drumming Chuan flowers and other traditional content and form of the game, change the boring movement and physical exercises into interesting imitative activities or the plot of the game.

In addition to the field investigation, there are a variety of forms and contents in field practice, such as field survival training, outdoor sports, field exercises and painting and so on. These needs to be carried out from the target and the content of the overall design, careful consideration [5].

\section{Exploitation and Utilization on Course Resources}

Curriculum resources are the essential and direct conditions for the formation of the elements of the curriculum and the implementation of the curriculum. The implementation of field practice requires a specific curriculum resources, including the natural environment, human resources, information resources, material resources and financial resources, etc. [6].

Natural environment resource is the concrete situation and the active object in the field practice course. In choosing the natural environment resources, the author thinks that we should follow the principle of local development and the typical choice, so as to realize the curriculum objectives and requirements of "developing the local curriculum resources development ability of the students". The so-called local development is the nearest obstacle far, selection students living in the world of the local natural environment resources as practice investigation object. The so-called typical, is the practice area with the typical study content, is advantageous to realize the multi-dimensional practice goal.

Human resource is the fundamental guarantee for the implementation of field practice curriculum, including the guidance of teachers, students themselves and the natural environment of the community organizations and personnel, including social media, social groups, etc..Among them, the guide is the organizer, the designer and the guide of the field practice, the students are not only the learners, but also the human resources of the course, which is composed of 4-6 students, due to the team members to make clear responsibility, self management, division of labor, become to ensure that an important condition for the field practice in an orderly and effective, safe conduct. Community organizations and personnel within the natural environment can provide support for the life support of the field practice, while the social media and social organizations, and even the local government's attention is to promote the implementation of the intangible power.

Information resources is an important condition for the implementation of field practice curriculum, mainly refers to the students in the practice of various information materials, including field practice manual, field record book, reference books and network resources, etc.. Material resources and financial resources are the essential prerequisite for the implementation of field practice curriculum.

Material resources include a topographic map of the geographic location of a practical area, an altitude meter, and a height meter, used to observe and photograph the plant, the ecological landscape of the telescope, digital camera and camera, etc..

Financial resources, we should strive for special funds for curriculum practice, for social organizations to cooperate to build, multi-channel fund-raising, to ensure the effective implementation of field practice. 


\section{Evaluation on Course Study}

Generally speaking, the activity curriculum takes the process evaluation and the result evaluation method to carry on the study evaluation, taking the activity as the carrier of the field practice course of study evaluation can learn from this kind of evaluation method. The so-called process evaluation is the evaluation in the field practice, mainly is the evaluation of the students in the activities of the attitude, the problem and the degree of development, according to the behavior observation of field practice, the process record and activity of field practice, the evaluation of students' self rating, mutual evaluation and guidance of teacher evaluation, the evaluation process of the evaluation process is reflected in the flexible use of the portfolio evaluation method, such as the evaluation of the archives, the evaluation and the performance evaluation. The so-called result evaluation is the evaluation of the activity after the end of the study, the main objective is to investigate the degree of the activity of the students and the development of the students' personality, the evaluation method is mainly the results of the evaluation, for example, field investigation can evaluate results in the form of the specimen (Biao Bence), web production, investigation summary, survey report, exhibition board [7].

\section{Evaluation and Analysis on Field Practical Course Model}

According to the arrangement and implementation of the curriculum and the specific teaching activities of the field, the practice mode of field education has become mature, and has a certain standard. From the perspective of educational goals, the main aspects of the following aspects of the significance:

First, this focus on the students' main body participation activities, and the main activities require students to have a lot of emotional input, therefore, the field of educational practice to achieve the students' emotional training objectives. Field education activities to provide students with more opportunities to contact with the students, and the students' intimacy, with the teacher's harmony, cooperation with other people, will make the students feel the impact of a number of aspects, feel happy, this will not only make students love life, but also easily to form a lively, cheerful, active quality, and can carry forward the unique style of the students. Students in outdoor education always face a certain task, in the process of forming and changing certain personality characteristics. In the outdoor education, the rich content, the form of activities with their own characteristics, way of the students' personality has a very broad impact, it can be said that the field of education practice of the students' personality development and improvement has a very important role.

Secondly, the practice of field education is helpful to the development of students' ability, especially for the improvement of the practical ability and creative thinking ability. Psychological research shows that the ability is the result of the activity. Outdoor education not only has an important influence on the development of students' general ability, but also has important effect on the students' practical ability and creative thinking ability. For example, in the outdoor organization of students to read, tell stories and other performances to cultivate, exercise students' memory, thinking ability, imagination and verbal expression ability, at the same time, the students are encouraged to develop their creative thinking ability and the ability to use the knowledge, these are important to improve the students' observation ability and the ability to operate.

Once again, the field education is also helpful to the students to obtain knowledge, and to some extent, it is more effective than classroom teaching. In the field teaching, the main discovery learning and inquiry learning, as well as the wide teaching scene provided by the field, can also cause the students' learning interest, thus improving their learning efficiency. $\square$ In particular, it is pointed out that the knowledge of skills, experience and knowledge of the problem is different from the logical and systematic knowledge, they have lower universal and systematic, but they are more specific, individual and operational. This kind of knowledge learning must be combined with the main activities, through the students' individual repeated independent operation, activity experience, thinking, to be able to make students to master and use, then achieve the skilled [8].Therefore, the 
teaching of this kind of knowledge is mainly through teaching activities, that is, the activity of the outdoor teaching is helpful to the acquisition of such knowledge. Compared to the school classroom education, field education activities to provide students with a wider world, more training opportunities, learning in practice, practice in the study.

\section{Conclusion}

In recent years, the research on the field investigation and training are the University's sports specialty which is from the angle of sports development training, field survival training, orientation training and so on; The Geography, physical geography, petrology and so on; general biology, environmental ecology; pharmaceutical botany; exploration technology and engineering; and the field of students survival training. Most of them are from the view of professional, the study is suitable for the characteristics of the field survival training program, or the construction of the field practice teaching base; They also study some talk about the professional ability, scientific thinking and practical ability. But with the characteristics of primary education specialty, the text of the field survival training is also very few. Mentioned several times in the primary school teachers professional standards, the national long-term development reform outline, to the develop students' practical ability, innovative thinking and so on. Therefore, the study is necessary and timely, with practice, theoretical value and innovation significance, and some significance and reference value.

Primary school education professional field practice curriculum training, breaking the people to the curriculum in the biological education, geography education and other science professional education system in the set of cognitive set, closely with the characteristics of primary school education specialty, focusing on the "field" as the main form of field practice. Through this kind of practice, guide students to design and implement the arrangement plan, for improving students' scientific research and practical ability, and with a significant effect on embodies the combination of theoretical teaching and scientific research practice; And through the trials and tribulations of field investigation, field research and rigorous and realistic, and for students to develop hard work, truth-seeking and truth-seeking, sharing and collaboration with the good qualities of the behavior, with its unique value and significance. Also specially trained the students to love nature, to understand the nature of the emotional attitude and values.

\section{Acknowledgement}

This work is supported by A-class teaching reform project of Liaoning Education Department in 2014 (UPRP20140249), The key issue of Liaoning economic and social development in 2015 (2015lslktzimzs-02), A-class teaching reform project of Bohai University in 2013 (JG13YB004), "Twelfth Five Year" planning project of Liaoning education and science in 2013 (JG13CB030).

\section{References}

[1] X. D. Huang, "Design and implementation of field practice course for primary education major in colleges and universities," Forum on Contemporary Education, vol. 56, no. 11, pp. 122-124, 2008.

[2] X. Q. Zhu, H. Zhang, " Feasibility study of field survival and development course in colleges and universities: Teaching practice based on field survival and development of Shenzhen university," Guizhou Sports Science and Technology, vol. 8, no. 3, pp. 22-25, 2013.

[3] Y. R. Huang, X. J. Wu, H. Li, et al, "Design and practice of field sports curriculum," Journal of Beijing Sport University, vol. 35, no. 3, pp. 971-973, 2008.

[4] X. Q. Zhu, H. Zhang, "Feasibility analysis of open field survival course in colleges and universities," Journal of Shenyang Normal University (Natural Science), vol. 18, no. 3, pp. 232-236, 2003. 
[5] G. Z. Wang, S. D. Qiu, "Design and implementati of outdoor trainning in outdoor survival education curriculum," Journal of Physical Education, vol. 17, no. 1, pp. 56-62, 2010.

[6] S. S. Li, "Practice oriented curriculum reform of elementary school teachers' pre service education: Taking Quanzhou normal university as an example," Education and Teaching Research, vol. 23, no. 9, pp. 1-4, 2009.

[7] H. Dong, L. Sun, L. Jin, "Research on the organization of college students living in the wild life," Journal of Zhangzhou Normal University (Natural Science), vol. 23, no. 3, pp. 97-89, 2008.

[8] J. H. Ma, "Study on the practice mode of outdoor education in primary and middle schools in the United States of America," Master's degree of Northwest Normal University, 2006. 